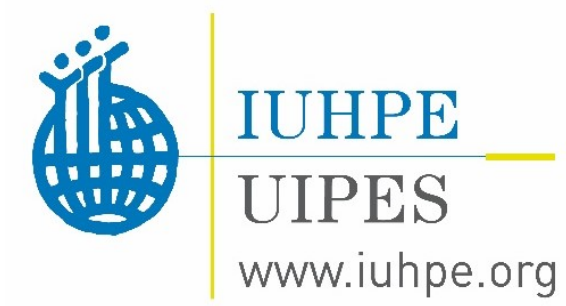

\title{
IUHPE Position statement on health literacy A practical vision for a health literate world
}




\section{Contact Information}

International Union for Health Promotion and Education - IUHPE

c/o Santé publique France

12 rue du Val d'Osne

94415 Saint-Maurice, France

International secretariat IUHPE-UIPES

c/o École de Santé Publique

Université de Montréal

7101 avenue du Parc, 3rd floor

Montréal QC H3N 1X9, Canada

www.iuhpe.org

Twitter: @IUHPE

Email: iuhpe@iuhpe.org

(C) 2018 International Union for Health Promotion and Education

This position statement was written by the IUHPE Global Working Group on Health Literacy. Active authors (alphabetically ordered): Janine Bröder, Peter Chang, Ilona Kickbusch, Diane Levin-Zamir, Evelyn McElhinney, Don Nutbeam, Orkan Okan, Richard Osborne, Jürgen Pelikan, Irving Rootman, Gillian Rowlands, Luis Nunes-Saboga, Robert Simmons, Kristine Sørensen, Stephan Van den Broucke, Stefania Velardo and Jane Wills. Scientific revision of Spanish translation: Paola Ardiles. It was approved in the IUHPE Executive Board meeting held in May 2018.

Please cite information contained in the document as follows: International Union for Health Promotion and Education (2018). IUHPE Position statement on health literacy: a practical vision for a health literate world. IUHPE Global Working Group on Health Literacy. Paris: IUHPE.

The International Union for Health Promotion and Education (IUHPE) is a global professional nongovernmental organisation dedicated to health promotion around the world for more than 65 years. The IUHPE operates a unique worldwide, independent, global, professional network of people and institutions committed to improving the health and wellbeing of the people through the integration of health in all policies, advocacy for effective health promotion, translation of research and workforce development.

Find out more at www.iuhpe.org. 


\section{TABLE OF CONTENTS}

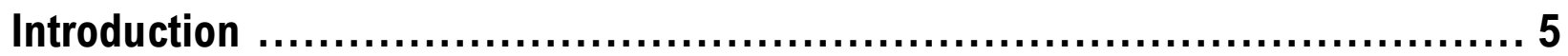

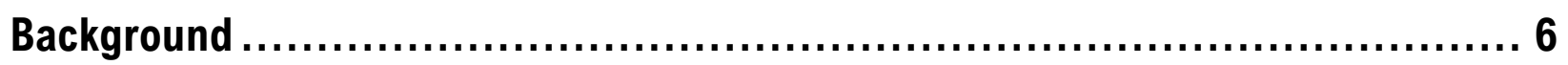

Health literacy has been more formally defined and conceptualized in multiple ways ..............6

Health literacy has been characterized in a number of ways .........................................

Health literacy is increasingly acknowledged as a determinant of health ............................

Action areas: policy, intervention, measurement and research, building capacity ...11

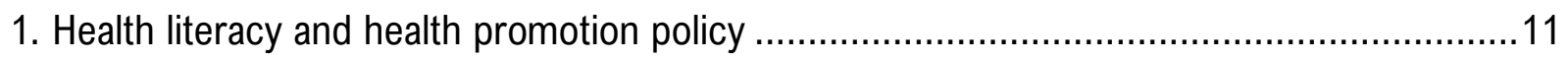

ACTION AREA: Promoting a systems approach to health literacy.............................12

ACTION AREA: Ensuring the inclusion of health literacy in global, national and regional policies, and strategies for health promotion and social determinants of health ..........................12

ACTION AREA: Recognizing that health literacy is content and context specific across the

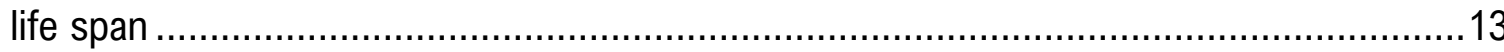

2. Health literacy is modifiable and responds to appropriate intervention .............................14

2.1 Patient education in clinical practice ....................................................... 14

2.2 Health literacy and health promotion interventions........................................... 15

ACTION AREA: Emphasizing that health literacy intervention is a people/ community-based

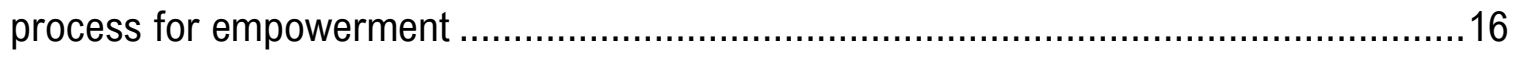

3. The growing evidence base of health literacy research ......................................... 17

ACTION AREA: Funding, producing and promoting research to contribute to the growing evidence base 18 
4. Building capacity and sharing knowledge, applying an inter-sectorial approach.................19

ACTION AREA: Workforce development strategies ................................................20

ACTION AREA: Identifying and engaging relevant stakeholders for collaborative health

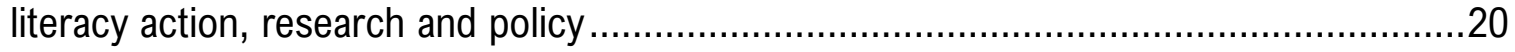

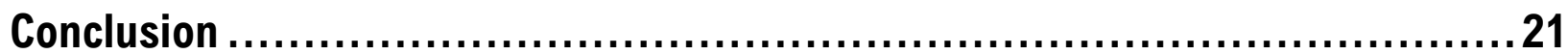

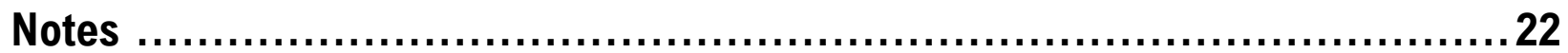

References.................................................................... 22 


\section{INTRODUCTION}

Since the 1990s, there has been a steep and steady rise in studies published, and national and international policies adopted, on health literacy. This surge in interest has focused on the definition of health literacy and its various measures, the relationship between health literacy, health promotion and a wide range of health and social outcomes, and increasingly, investment in policy and programs to improve health literacy in populations.

The Position Statement is a mechanism by which we describe what we believe to be the current state of the art and how it can be promoted through adoption by key stakeholders. 


\section{BACKGROUND}

Health literacy has been more formally defined and conceptualized in multiple ways

Health literacy is the combination of personal competencies and situational resources needed for people to access, understand, appraise and use information and services to make decisions about health. It includes the capacity to communicate, assert and act upon these decisions. Health literacy responsiveness describes the way in which services, organizations and systems make health information and resources available and accessible to people according to health literacy strengths and limitations (1).

The breadth of the variations of the definition of health literacy, an evolving concept, has been documented and systematically updated in the scientific literature (2-4). The application of the concept varies markedly from country to country, between public health and clinical care, between government and civic society groups, and is applied on the individual, the community, the institutional/organizational, the national and global levels. More specific aspects and subdimensions of health literacy have evolved and been developed and validated, with relation to specific illness, age-groups, and in new contexts such as eHealth literacy, mental health literacy, media health literacy and nutrition literacy. In an era characterized by rapid technological change, there is also increasing emphasis on digital health literacy and e-health literacy, defined as the ability to seek, find, understand, and appraise health information from electronic sources and apply the knowledge gained to addressing or solving a health problem and others $(5,6)$.

The concept of health literacy has also developed in two distinctive contexts and specific perspectives - in clinical care where low health literacy is viewed as a risk factor for poor health and poor compliance with health care advice; and in public/community health where health literacy can be viewed as a personal and population asset offering greater autonomy and control over health decision-making in order to increase individual empowerment and act upon the social determinants of health $(7-10)$. 


\section{Health literacy has been characterized in a number of ways}

The skills identified within the various concepts of health literacy have been characterized in different ways, but the most commonly used form reflects the typology of literacy described above as functional, interactive and critical health literacy (11).

Functional health literacy describes the possession of literacy, knowledge, and other skills sufficient to acquire and act on information on defined health risks and recommended health services use, often associated with recommended health and disease management strategies. This reflects the outcome of some forms of health education, and patient education in a clinical setting that is based on the communication of information on health risks, including navigation of the health system. Generally, such activities will result in individual benefit, but may be directed towards population benefit (for example by promoting participation in immunization and screening programs). Typically, such approaches do not invite interactive communication, and may not foster skills development and autonomy in health-related decision-making.

Measures of functional health literacy have been tested, refined and validated over the past 20 years to provide short screening tools for clinicians to use in everyday practice with a broad range of populations (12-14). These measures were designed and are most useful as screening tools in clinical practice but are generally insufficient to measure the relative differences in cognitive skills and their application as described above (15).

Interactive health literacy describes the skills required to extract, understand and discriminate between health information from different sources, and to apply new information to changing circumstances. This reflects the outcome of health promotion interventions to focus on the development of personal skills and improved personal capacity to act independently, and designed to improve motivation and self-confidence to act on information obtained. This type of intervention is generally more interactive and often implemented through more structured settings (for example, school health education, well-designed interactive web-sites). As the description implies, these skills also enable a higher level of interaction with clinical, public and digital information sources. 
Critical health literacy describes the most advanced cognitive and social skills which can be applied to critically analyse health information from a variety of sources, and to use this information to exert greater control over both personal health decisions and wider influences on those decisions. Within this domain, health education may not only involve the communication of information on personal health risks, but also on the social, economic and environmental determinants of health. In this way, critical health literacy is often conceptualized as a form of health citizenship that empowers people to join together in social and political processes to modify determinants of health (16). Accordingly, this type of health literacy can be more obviously linked to population benefit, alongside benefits to the individual.

This classification of health literacy helps to distinguish between the different skills that progressively enable greater autonomy in decision-making, as well as in a wider range of health actions that extend from personal behaviours to social action that address the underlying determinants of health. As with general literacy, differences between individuals will be observable based on exposure to different forms of information (content and media), and the self-confidence to respond to health communications, associated with self-efficacy.

As a concept, health literacy has attracted the attention of researchers, clinicians, public health practitioners and policy makers. For researchers interested in health and disease causality, health literacy offers a convenient and logical summary definition of health status/risk that can be used to understand and explain variation in health and disease outcomes. For those interested in the evaluation of information, education and communication (IEC) interventions, health literacy has long been proposed as a useful outcome measure $(11,17)$. 


\section{Health literacy is increasingly acknowledged as a determinant of health}

Measurement tools for comprehensive health literacy have been developed and tested over the past decade, and applied to population studies $(18,19)$. More and complex tools have emerged and been tested and applied widely in national and international health literacy surveys (20-22). The results of these surveys and studies show that the instruments can discriminate between relative differences in health literacy, and importantly, can be used to assess change in individuals and populations following health promotion interventions. Health literacy measurement tools have also been developed with more specific foci, including specialised instruments for specific populations (23-25); health content (26-30); communication media $(5,6,31)$; and different countries $(32,33)$. Currently, work is underway in several countries to develop and adapt existing measures to local contexts.

A consistent finding of these studies shows there is a clear social gradient for health literacy, and limited health literacy has been shown to be associated with:

- Worse health outcomes

- Decreased use of preventive health services; increased use of medical services

- Less ability to manage long term conditions

- Disproportionate impact on socio-economically disadvantaged population groups, older people, migrants, ethnic minority groups and people with disabilities.

People who have better developed health literacy will thus have skills and capabilities that enable them to engage in a range of health enhancing actions including changing personal behaviours, as well as social actions for health and the capability of influencing others towards healthy decisions such as quitting smoking, or participating in preventative screening programs. The results are not only improved health outcomes but also a wider range of options and opportunities for health. 


\section{KEY SUMMARY POINTS}

- Health literacy is an observable, measurable outcome from health education/promotion interventions;

- Higher levels of health literacy can support a wide range of health actions to improve health, prevent and better manage ill-health, including changed personal behaviours, social actions for health, and influencing others towards healthy decisions.

Limited health literacy is therefore a threat to the outcome of health care, to improving population health and to achieving health equity. 


\section{ACTION AREAS: POLICY, INTERVENTION, MEASUREMENT AND RESEARCH, BUILDING CAPACITY}

Four priorities for the advancement of health literacy with their respective action areas have been identified.

\section{Health literacy and health promotion policy}

Health literacy is relevant to all areas of health promotion action defined in the WHO Ottawa Charter on Health Promotion: building healthy public policy, creating supportive environments, strengthen community action, developing personal skills and reorienting the health system. For public health policy, for organizations, and for health promotion professionals in particular, health literacy assessment enables a more complete understanding of needs of individuals, families and communities. Awareness of, and attention given to health literacy, contribute to health promotion planning and advocacy, to designing programs and policies to improve individual and community health, and to promoting health equity.

The WHO, throughout the past decade, has continued to emphasize health literacy within health promotion policy initiatives and strategies. Health literacy was one of the main themes of the $7^{\text {th }}$ WHO Global Conference on Health Promotion held in Nairobi in 2009. The WHO publication entitled Health Literacy - The Solid Facts was published in 2013 primarily for the use by policy makers (34). Most recently, health literacy was named as one of the three action areas in the Shanghai Charter on Health Promotion ratified at the $9^{\text {th }}$ WHO Global Conference on Health Promotion in Shanghai 2016 (35). Health literacy has also been integrated into other policy directives beginning with Sustainable Development Goals (SDGs) (36), Non-Communicable Diseases (NCDs) and others (37).

WHO regions have been active as well. The Southeast Asian Region applied the use of a health literacy toolkit, developed in partnership with the Deakin University in Melbourne, launched in 2015. The first WHO Collaborating Center on Health Literacy was launched in October 2017 in Deakin University, Melbourne, Australia. 
National policies on health literacy have been developed and released, notably in Canada, Scotland, Wales, Ireland, Australia, and Austria. A comprehensive review of health literacy policy action can be found in the publication entitled Health Literacy as a Political Choice (38).

ACTION AREA: Promoting a systems approach to health literacy at the global, international, national and local levels. This approach strives to enhance health literacy on the individual/family level as well as through settings in the community and beyond. Major gains in health and equity can be made by ensuring health resource provision is systematic and provided in multiple formats, maximizing health learning opportunities across all of society. Health education and promotion programs should not only ensure appropriately tailored information is provided, but formats, modes (written, oral, mass media, social media, etc.) reach beyond the general population to empower minorities and disempowered groups including Indigenous groups, women and displaced peoples. To support such changes, health literacy considerations should be included at all levels, i.e., in policy and programs across systems settings such as: schools and education settings, workplace, social services, healthcare and other settings/systems.

ACTION AREA: Ensuring the inclusion of health literacy in global, national and regional policies, and strategies for health promotion and social determinants of health

Research shows a strong connection between health literacy and social determinants of health, thus aiding in identifying populations at risk for low health literacy. As a health asset, health literacy can be developed, and is responsive to health promotion intervention. The role of health literacy in reducing health disparities, and the prevention and treatment of communicable and noncommunicable diseases should be considered in health promotion planning. As such, greater awareness among policy and decision makers of the importance of health literacy is necessary. 
ACTION AREA: Recognizing that health literacy is content and context specific across the life span

Accepting health literacy as an asset for children, adolescents, adults, and the elderly goes hand in hand with the development of health literacy responsive environments and settings, and the development of particular competencies relevant for each age group. This approach recognizes the diversity of cultural, social, and economic backgrounds, that directly or indirectly affect personal health literacy, health-related behaviors, and by that, health outcomes. Consequently, policies and actions related to health literacy must be responsive to different contexts to ensure that their content is appropriate for the people they address. It is necessary to ensure that services and organizations actively seek to monitor and understand the health literacy of the people they serve and respond equitably. Examples of this approach are health literacy responsive or health literate settings, such as hospitals and health services, workplaces, schools, communities and more. All settings should strive to develop health literate attributes in their use of information and communication, including navigable environments. Most recently the WHO European Region has published a policy brief highlighting the co-benefits for the education sector when implementing targeted health literacy action in children and young people in schools, specifically pointing to improved academic performance, positive influence on education, improved physical and emotional health, general long-term benefits across the life course, and economic benefits for children when they reach adulthood (39). 


\section{Health literacy is modifiable and responds to appropriate intervention}

While health literacy is increasingly seen as a determinant of health (40), it is also viewed as an important outcome of health promotion interventions (37). A comprehensive review including mainly this type of intervention reports on the outcomes of 38 intervention studies (41). They provide broadly consistent evidence that comprehension of health information and advice among individuals with low health literacy can be improved through modifications to communication, and that intensive mixed-strategy interventions (for example combining adapted communications with behavioural skills coaching) produces improved health outcomes including reduced reported disease severity, unplanned emergency department visits and hospitalizations. The authors concluded that there have been "significant advances in the field of health literacy research" since an earlier 2005 review (42).

\subsection{Patient education in clinical practice}

Effective clinical practice will facilitate both improved prevention and better management particularly of chronic non-communicable diseases (43). The restricted time available in clinical consultations will often limit communication to factual information on health risks, and on how to use medications and health care services. Patient education of this type will often be directed towards well defined outcomes - such as achieving participation in screening programs and/or compliance with the use of prescribed medicines. Patient education in the clinic can also contribute to the development of a wider range of knowledge and skills necessary for successful selfmanagement of NCDs such as diabetes and heart disease, and related clinical risks such as hypertension, elevated cholesterol, or obesity. The effects of poor health literacy can be mitigated by improving both the quality of health communications, and greater sensitivity among health professionals and policy makers to the potential impact of low literacy on individuals and in populations. Such responses can be observed in a range of adaptations to traditional patient and population health education methods in print, broadcast and electronic communication, as well as improved interpersonal communication between the public and health care providers. 
There is a growing number of examples of different approaches to patient education that are intended to improve functional health literacy and related clinical outcomes. The great majority of these studies are using the health literacy concept to better understand the likely response of patients to clinical advice and instruction, the impact on compliance, and longer-term success in disease management. In this context, low health literacy is understood as a risk to successful clinical care. By using the screening instruments described earlier, such as Rapid Estimate of Adult Literacy Medicine (REALM) (44) and New Vital Sign (NVS) (45), clinicians can quickly and practically identify individuals with poor health literacy and modify their communications accordingly. The Joint Commission International ( $\mathrm{JCl}$ ) responsible for accrediting health care organizations, has included health literacy in its gold standards (6 $6^{\text {th }}$ edition 2017) (46).

Despite evident progress, the constraints on patient education in a clinical setting often mean that the educational methods used do not enable interactive communication, nor support a high level of autonomy in decision-making.

\subsection{Health literacy and health promotion interventions}

Higher levels of health literacy in a population support a wide range of health actions to improve health, prevent and better manage ill-health, including greater capacity to change personal behaviours, take social actions for health, and influence others towards healthy decisions. To achieve this, interventions that are context and content relevant - linked to critical life stages (e.g. adolescence, parenthood, aging and retirement) and events (e.g. diagnosis of chronic disease) are likely to be more successful in producing sustainable change. Health education is most likely to improve health literacy when the messaging and delivery are tailored to the specific needs of individuals and populations across their life course. There is growing evidence that health literacy may be improved through, for example, structured, theory-informed educational programs, or through similarly designed online learning programs. Many people have a far wider range of communication channels open to them. This enables access to a wide variety of sources of information and opens opportunities for more personalised and tailored health communication. Successful interventions tend to be based on more interactive and personalized forms of communication and messaging. 
Interventions to improve health literacy need to be viewed in the wider context of a comprehensive and integrated set of actions to promote health, prevent and manage ill-health in populations. Health institutions and settings play a key role in facilitating reliable and trustworthy health information within a context in which anyone can post health-related information. The increasing number of users on social media, the frequency of use, and the interaction they generate have raised the need for increasing attention given in health promotion interventions to digital health literacy.

As acknowledged, health literacy on the individual level does not depend solely on personal skills, but also on the demands and availability of resources available in the complexity of situations in which health decisions and actions occur. Therefore, health literacy sensitive settings, organizations and systems play a central role as they do in comprehensive health promotion models.

ACTION AREA: Emphasizing that health literacy intervention is a people/ community-based process for empowerment

Accepting health literacy as an asset for people throughout the lifespan - childhood, adolescence, adulthood and among elderly argues that responding to health literacy needs should be supported as a people- and community- centered process for citizen empowerment. Promoting and supporting individuals and communities to build health literacy skills are critical, not only for making informed choices for their and their family's health, but also to proactively engage in health, education, labor, and other systems to generate positive changes in their societies. Interventions for improving health literacy need to be viewed in the wider context of a comprehensive and integrated set of actions to promote health. Civil society can explore and develop the potential of health education not only to enable individual change but also to strengthen collective action for health $(47,48)$. 


\section{The growing evidence base of health literacy research}

As noted in the Background section above, the scientific basis for measuring health literacy on the individual, community, clinical and population levels has grown enormously, so much so that an online database of health literacy measures was developed by Boston University, entitled The Health Literacy Tool Shed database (49). Historically, measuring health literacy has undergone three different phases or "traditions" (50), from emphasizing literacy (functional) to healthcare specific health literacy, and on to a more comprehensive measure looking at self-reported health literacy in relation to the complexity of contexts (19).

Even with the tremendous expansion of research, different measurement tools will be required for different ages and stages in life - even if the structure of the concept remains constant. For example, assessing the health literacy of students in school will require different propositions compared to assessing the health literacy of older people with chronic disease. More sensitive measures will be required to distinguish between functional, interactive and critical health literacy including social skills such as those involved in negotiation and advocacy. Gaps in measures identified by the architects of the Health Literacy Tool Shed include: aligning health literacy measurement with theory and conceptual models, developing methods of objective measurement that approximate the convenience of self-report measures, conducting comparative assessment of self-reported and objective measures. Most importantly, health literacy measurement tools should be used more frequently during health literacy promoting interventions in order to measure change over time and allow gaining insights into the development of health literacy and how certain determinants, such as skill development, education, and socioeconomic status interact with and influence health literacy. 
ACTION AREA: Funding, producing and promoting research to contribute to the growing evidence base

This includes measuring and assessing health literacy and applying knowledge within the context of health promotion. The IUHPE calls for the inclusion and prioritizing of health literacy in research protocols. Systems for monitoring change and improvement in health literacy along the social gradient should be established, monitored and sustained, particularly where investment has been made in action and intervention. The role of organizations and the settings approach for promoting health, applying health literacy appropriate action needs to be further researched. Additionally, the need for promoting health literacy in a digital world, as a vehicle for health promotion offers many research questions. More action needs to be taken to support sustainable health literacy programs, addressing the root causes of ill health, applying a salutogenic approach, as well as health literacy promoting interventions addressing individuals, collectives, and policy and decision makers.

Health literacy can, and is, improved by access to digital platforms. These digital platforms are increasingly social in nature and can provide access to resources from healthcare practitioners, organisations or members of the public. The health literacy practices enacted in these social areas often include social skills as well as learning with, and from, others in social networks. However, people need confidence and digital capabilities to access the information and resources available in these platforms to use them to their full potential and influence individual and community health literacy. We acknowledge that there needs to be governmental responsibility through education and policy to ensure these digital capabilities are provided to all across the lifespan, ensuring that further gaps in the social gradient which influence health literacy are not widened. 


\section{Building capacity and sharing knowledge, applying an inter-sectorial}

approach

In recent years, a growing number of opportunities and frameworks for professional capacity building initiatives on health literacy have taken place, in diverse formats including global, national and regional conferences, university schools of public health courses, summer schools and institutes,

For policy-makers, the concept of health literacy is sufficiently diverse to be used to support a full spectrum of policy positions. Improving health literacy can be represented to citizens and the public at large as supporting a policy commitment to greater patient and public engagement in health decision-making - nicely summarized by the "no decision about me without me" mantra of the National Health System in the United Kingdom; and it can also be represented as offering a structure for nationally coordinated health education campaigns such as China's longstanding Patriotic Health Campaign, now informed and monitored by a national health literacy survey. In both these examples the concept of health literacy has been interpreted and adapted in ways that are locally relevant to clinical and public health policy and practice.

For clinicians, work over many years, mainly in the USA, has established low health literacy as an identifiable and manageable risk in clinical care. In particular, the importance of health literacy has been recognized in the management of long-term and complex conditions - including and especially NCDs - that depend upon successful patient engagement and management (37). Identification and successful management of the risk of low health literacy, and delivery of tailored patient education has been demonstrated to be feasible and effective in a wide variety of circumstances.

For health promotion and public health practitioners, in the government and non-government sectors, health literacy is embraced as a personal and organizational asset that can be developed through interventions to support greater personal autonomy and community control over a range of determinants of health. This fits comfortably with a more holistic understanding of the social determinants of health, and greater sophistication in the methods and content necessary in a comprehensive, integrated health promotion program (51). 
ACTION AREA: Workforce development strategies should include the development of health literacy competences and should be included in training/education of all health and educational professionals. Likewise, more knowledge and experience should be shared within interdisciplinary and inter-sectoral contexts, developing networks and communities of practice among professions and sectors nationally and internationally. Health literacy should be included in higher education and vocational training in all relevant fields.

ACTION AREA: Identifying and engaging relevant stakeholders for collaborative health literacy action, research and policy

It is important to build synergies and enhance partnerships organizations to raise the profile of health literacy on the collective agenda. Cross-sectoral initiatives should be institutionalized across academia, government, civil society as well as the public and private sector to improve health literacy. As in best practice for health promotion, on local and community levels, culturally accepted leadership should be engaged to co-create or adapt interventions and policy to health literacy needs (52). 


\section{CONCLUSION}

In conclusion, the role of health literacy is recognized as a cross-cutting issue, and its relative importance as a health determinant is understood as is its potential for use to guide clinical practice, public health interventions and public policy for the advancement of global health. The IUHPE hereby calls upon the global public health community to support the development and dissemination of excellence in health literacy research, policy and practice.

The IUHPE calls for global champions and leaders to show their commitment to global, regional and national governance grounded in partnership and co-production of health. 


\section{NOTES}

Acknowledgement of supporting policy documents: Nutbeam (37); Sorensen (38); Kickbusch et al. (34).

\section{REFERENCES}

1. Brach C, Keller D, Hernandez LM, Baur C, Dreyer B, Schyve P, Lemerise AJ, et al. Ten attributes of health literate health care organizations. Washington, DC: Institute of Medicine of the National Academies; 2012 Jun.

2. Peerson A, Saunders M. Health literacy revisited: what do we mean and why does it matter? Health Promot Int. 2009 Apr 16;24(3):285-96.

3. Sørensen K, Van den Broucke S, Fullam J, Doyle G, Pelikan J, Slonska Z, Brand H. Health literacy and public health: a systematic review and integration of definitions and models. BMC Public Health. 2012 Dec;12(1):80.

4. Malloy-Weir LJ, Charles C, Gafni A, Entwistle VA. Empirical relationships between health literacy and treatment decision making: a scoping review of the literature. Patient Educ Couns. 2015 Mar 1;98(3):296-309.

5. Norman CD, Skinner HA. eHealth literacy: essential skills for consumer health in a networked world. J Med Internet Res. 2006 Apr;8(2).

6. Levin-Zamir D, Lemish D, Gofin R. Media Health Literacy (MHL): development and measurement of the concept among adolescents. Health Educ Res. 2011 Apr 1;26(2):323-35.

7. Nutbeam D. The evolving concept of health literacy. Soc Sci Med. 2008 Dec 1;67(12):2072-8.

8. Pleasant A, Kuruvilla S. A tale of two health literacies: public health and clinical approaches to health literacy. Health Promot Int. 2008 Jun 1;23(2):152-9.

9. Mårtensson L, Hensing G. Health literacy-a heterogeneous phenomenon: a literature review. Scand J Caring Sci. 2012 Mar;26(1):151-60.

10. Van den Broucke S. Health literacy: a critical concept for public health. Arch Public Health. 2014 72:10. 
11. Nutbeam D. Health literacy as a public health goal: a challenge for contemporary health education and communication strategies into the 21st century. Health Promot Int. 2000 Sep 1;15(3):259-67.

12. Davis TC, Long SW, Jackson RH, Mayeaux EJ, George RB, Murphy PW, Crouch MA. Rapid estimate of adult literacy in medicine: a shortened screening instrument. Fam Med. 1993 Jun;25(6):391-5.

13. Parker RM, Baker DW, Williams MV, Nurss JR. The test of functional health literacy in adults. J Gen Intern Med. 1995 Oct 1;10(10):537-41.

14. Weiss BD, Mays MZ, Martz W, Castro KM, DeWalt DA, Pignone MP, Mockbee J, Hale FA. Quick assessment of literacy in primary care: the newest vital sign. Ann Fam Med. 2005 Nov 1;3(6):514-22.

15. Manning DL, Dickens C. Health literacy: more choice, but do cancer patients have the skills to decide? Eur J Cancer Care. 2006 Dec;15(5):448-52.

16. Kickbusch I. Health literacy: engaging in a political debate. Int J Public Health. 2009 May 1;54(3):131-2.

17. Paasche-Orlow MK, Wolf MS. The causal pathways linking health literacy to health outcomes. Am J Health Behav. 2007 Aug 1;31(1):S19-26.

18. Osborne RH, Batterham RW, Elsworth GR, Hawkins M, Buchbinder R. The grounded psychometric development and initial validation of the Health Literacy Questionnaire (HLQ). BMC Public Health. 2013 Dec;13(1):658.

19. Sørensen K, Pelikan JM, Röthlin F, Ganahl K, Slonska Z, Doyle G, Fullam J, Kondilis B, Agrafiotis D, Uiters E, Falcon M. Health literacy in Europe: comparative results of the European health literacy survey (HLS-EU). Eur J Public Health. 2015 Dec 1;25(6):1053-8.

20. Rudd RE. Health literacy skills of US adults. Am J Health Behav. 2007 Aug 1;31(1):S8-18.

21. Chinn D, McCarthy C. All Aspects of Health Literacy Scale (AAHLS): developing a tool to measure functional, communicative and critical health literacy in primary healthcare settings. Patient Educ Couns. 2013 Feb 1;90(2):247-53. 
22. Jordan JE, Buchbinder R, Briggs AM, Elsworth GR, Busija L, Batterham R, Osborne RH. The Health Literacy Management Scale (HeLMS): A measure of an individual's capacity to seek, understand and use health information within the healthcare setting. Patient Educ Couns. 2013 May 1;91(2):228-35.

23. Chisholm MA, Fair J, Spivey CA. Health literacy and transplant patients and practitioners. Public health. 2007 Oct 1;121(10):800-3.

24. Wu AD, Begoray DL, MacDonald M, Wharf Higgins J, Frankish J, Kwan B, Fung W, Rootman I. Developing and evaluating a relevant and feasible instrument for measuring health literacy of Canadian high school students. Health Promot Int. 2010 May 13;25(4):444-52.

25. Paskulin LM, Aires M, Valer DB, Morais EP, Freitas IB. Adaptation of an instrument to measure health literacy of older people. Acta Paulista de Enfermagem. 2011;24(2):271-7.

26. Renkert S, Nutbeam D. Opportunities to improve maternal health literacy through antenatal education: an exploratory study. Health Promot Int. 2001 Dec 1;16(4):381-8.

27. Ohnishi M, Nakamura K, Takano T. Improvement in maternal health literacy among pregnant women who did not complete compulsory education: policy implications for community care services. Health Policy. 2005 May 1;72(2):157-64.

28. Ishikawa $\mathrm{H}, \mathrm{Yano} \mathrm{E}$. The relationship of patient participation and diabetes outcomes for patients with high vs. low health literacy. Patient Educ Couns. 2011 Sep 1;84(3):393-7.

29. Al Sayah F, Majumdar SR, Williams B, Robertson S, Johnson JA. Health literacy and health outcomes in diabetes: a systematic review. J Gen Intern Med. 2013 Mar 1;28(3):444-52.

30. Dumenci L, Matsuyama R, Riddle DL, Cartwright LA, Perera RA, Chung H, Siminoff LA. Measurement of cancer health literacy and identification of patients with limited cancer health literacy. J Health Commun. 2014 Oct 14;19(sup2):205-24.

31. Mitsutake S, Shibata A, Ishii K, Okazaki K, Oka K. Developing Japanese version of the eHealth literacy scale (eHEALS). [Nihon koshu eisei zasshi] Japanese journal of public health. 2011 May;58(5):361-71. 
32. Van der Vaart R, Drossaert CH, Taal E, Peter M, Hilderink-Koertshuis RT, Klaase JM, van de Laar MA. Validation of the Dutch functional, communicative and critical health literacy scales. Patient Educ Couns. 2012 Oct 1;89(1):82-8.

33. Suka $M$, Odajima $T$, Kasai $M$, Igarashi $A$, Ishikawa $H$, Kusama $M$, Nakayama $T$, Sumitani $M$, Sugimori H. The 14-item health literacy scale for Japanese adults (HLS-14). Environ Health Prev Med. 2013 Sep;18(5):407.

34. Kickbusch IL, Pelikan JM, Apfel F, Tsouros AD. The solid facts: Health literacy. Denmark: The World Health Organisation Regional Office for Europe; 2013.

35. World Health Organization. Shanghai declaration on promoting health in the 2030 Agenda for Sustainable Development. Health Promot Int. 2017 Feb 1;32(1):7.

36. United Nations Development Program Sustainable Development Goals. 2016 January. [Cited 2018 April 15]. Available at: http://www.undp.org/content/undp/en/home/sustainabledevelopment-goals.html

37. Nutbeam D. Discussion paper on promoting, measuring and implementing health literacy: Implications for policy and practice in non-communicable disease prevention and control. [Internet]. World Health Organization GCM/NCD Working Group 3.3 2017. [Cited 2018 April 15] Available at: http://www.who.int/global-coordination-mechanism/news/Health-literacyWHO-Geneva-Nov-2015.pdf

38. Sorensen K. Health Literacy as a Political Choice - A guide for politicians and decision makers, Global Health Literacy Academy; 2016.

39. McDaid D. Investing in health literacy. What do we know about the co-benefits to the education sector of actions targeted at children and young people. World Health Organization. European Observatory on Health Systems and Policies, Copenhagen: WHO Regional Office for Europe; 2016

40. Rowlands G, Shaw A, Jaswal S, Smith S, Harpham T. Health literacy and the social determinants of health: a qualitative model from adult learners. Health Promot Int. 2015 Sep 28;32(1):130-8.

41. Sheridan SL, Halpern DJ, Viera AJ, Berkman ND, Donahue KE, Crotty K. Interventions for individuals with low health literacy: a systematic review. J Health Commun 2011 Sep 30;16(sup3):30-54. 
42. Pignone M, DeWalt DA, Sheridan S, Berkman N, Lohr KN. Interventions to improve health outcomes for patients with low literacy. J Gen Intern Med. 2005 Feb 1;20(2):185.

43. Coulter A, Ellins J. Effectiveness of strategies for informing, educating, and involving patients. Br Med J. 2007 Jul 5;335(7609):24-7.

44. Davis TC, Long SW, Jackson RH, Mayeaux EJ, George RB, Murphy PW, Crouch MA Fam Med. 1993 Jun; 25(6):391-5.

45. Weiss BD, Mays MZ, Martz W, Castro KM, DeWalt DA, Pignone MP, Mockbee J, Hale FA Ann Fam Med. 2005 Nov-Dec; 3(6):514-22.

46. Joint Commission for Healthcare Accreditation [Internet], 2017 [Cited 2018 April 15]. Available from: https://www.jointcommissioninternational.org/jci-accreditation-standards-forhospitals-6th-edition/.

47. Levin-Zamir D, Leung AY, Dodson S, Rowlands G. Health literacy in selected populations: Individuals, families, and communities from the international and cultural perspective. Inf Serv Use. 2017 Jan 1;37(2):131-51.

48. Dodson S, Good S, Osborne R. Health literacy toolkit for low and middle-income countries: a series of information sheets to empower communities and strengthen health systems. New Delhi: World Health Organization, Regional Office for South-East Asia; 2015.

49. Health Literacy Tool Shed. Boston (MA): Boston University [cited 2018 Sept 1]. Available from: https://healthliteracy.bu.edu/.

50. Pelikan JM, Ganahl K. Measuring health literacy in general populations: Primary findings from the HLS-EU consortium's health literacy assessment effort. Health Lit Res Pract. 2017 Oct 18:34-59.

51. Rootman I, Gordon-El-Bihbety D. A vision for a health literate Canada. Ottawa, ON: Canadian Public Health Association; 2008.

52. Trezona A, Rowlands G, Nutbeam D. Progress in Implementing National Policies and Strategies for Health Literacy: What Have We Learned so Far? Int. J Environ Res Public Health. 2018, 15, 1554. 


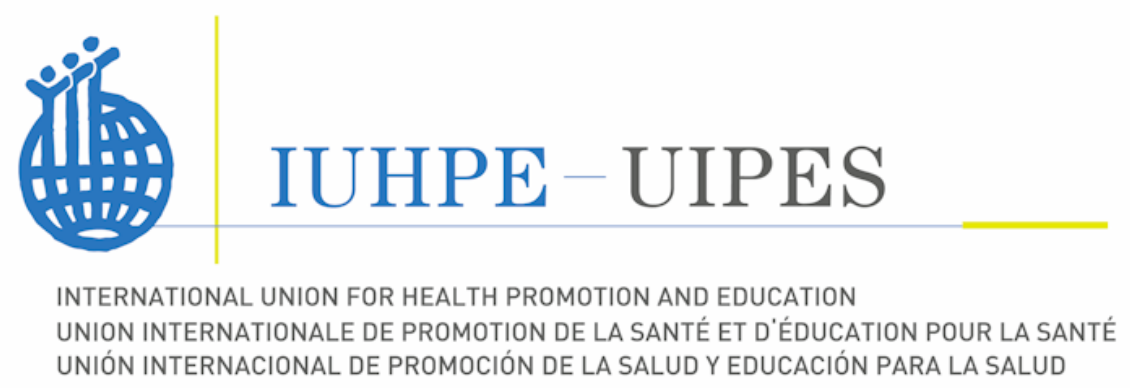

IUHPE Headquarters

c/o Santé publique France

12 rue du Val d'Osne

94415 Saint-Maurice, France
International secretariat IUHPE-UIPES

c/o École de Santé Publique

Université de Montréal

7101 avenue du Parc, 3rd floor

Montréal QC H3N 1X9, Canada

www.iuhpe.org

Twitter: @IUHPE

Email: iuhpe@iuhpe.org 